\title{
IDEAS: Interdisciplinary Design Engineering and Service
}

\author{
Ruth E. Davis \\ Associate Dean, Undergraduate Studies \\ School of Engineering \\ Santa Clara University \\ rdavis@scu.edu \\ Tonya. L. Nilsson \\ Lecturer, Civil Engineering \\ School of Engineering \\ Santa Clara University \\ tnilsson@scu.edu
}

\author{
Shoba Krishnan \\ Associate Professor of Electrical Engineering \\ School of Engineering \\ Santa Clara University \\ skrishnan@scu.edu \\ Patti Fylling Rimland \\ Senior Administrative Assistant to the Associate Dean \\ School of Engineering \\ Santa Clara University \\ primland@scu.edu
}

\begin{abstract}
This paper describes the development of the IDEAS: Interdisciplinary Design Engineering and Service program. This program supports and promotes communitybased projects as a vehicle for providing students with real-world experience working with clients to solve need-based problems. IDEAS supports senior design projects, an interdisciplinary course on community-based projects, as well as extra-curricular projects through various student organizations. A complete description of the course, common projects and challenges is provided. We describe the benefits of developing long-term community partnerships. Student self-assessments of skills gained shows the course to be successful in providing engineering design experience and soft skills as well as professional sense of the positive societal impact of engineering projects. Course demographics show these projects attract a higher percentage of underrepresented groups than in the overall engineering student population.
\end{abstract}

Index Terms - Community-based projects, engineering design, engineering education, service learning

\section{INTRODUCTION}

"Tell me, and I forget. Teach me, and I remember. Involve me, and I learn." , This famous quote by Ben Franklin was a driving force in the development of our service learning program. Service learning supports the mission of Santa Clara University's School of Engineering to prepare our students for professional excellence, responsible citizenship, and service to society. To achieve this, our students must develop proficiency in engineering and science principles as well as an understanding of community needs and an ability to address those needs under a variety of constraints. A study by the Higher Education Research Institute of 22,236 college undergraduates attending a sample of national baccalaureate granting colleges and universities determined a service learning experience positively affected students' preparation in the areas listed above. ${ }^{\text {ii }}$ Further, our university promotes the development of competence, conscience and compassion in our students and we have found that community-based projects, both local and global, provide our students the opportunity to develop these skills to make a positive impact on the world around them. 
Service learning also provides students the experience to build their soft skills, including teamwork, communication, professionalism and global awareness. Since the introduction of ABET EC 2000, universities in the U.S. have been required to demonstrate their students have met learning outcomes around these soft skills. ${ }^{\text {iii }}$ Service learning experiences integrated into the curriculum provide a valuable tool for departments in meeting ABET outcomes.

We began our involvement with community-based projects in 1999 through participation in the Virtual Development Center (VDC), an initiative of Anita Borg's Institute for Women and Technology. We engaged the community with daylong brainstorming sessions based on the creation of a Thinking Environment ${ }^{\mathrm{TM}}$ to encourage open collaboration among all participants, technical and non-technical. Some of these first projects involved organizations that supported dislocated women and children and their needs and involved partnerships with InnVision and HomeSafe, a shelter for women and their children who were survivors of spousal abuse. ${ }^{\text {iv }}$ In 2005, our efforts expanded beyond the local community, supporting several community-based projects in El Salvador through collaboration with engineering students and faculty at the Universidad Centroamericana Jose Simeon Canas (UCA). In a country ravaged by civil war and prone to frequent earthquakes, projects were focused on clean water distribution, alternative energy, development of earthquake resistant building materials, and low cost cargo transport (via a human-powered utility vehicle). Through these projects we discovered that community-based projects were particularly attractive to women and other underrepresented groups in our School of Engineering (SOE). ${ }^{\mathrm{v}}$

We established a goal to set up the infrastructure to make it possible for EVERY engineering student to participate in a community-based project at some point during his or her Santa Clara University education. We institutionalized our efforts by starting a program we named IDEAS (Interdisciplinary Design Engineering And Service). ${ }^{\mathrm{vi}}$

\section{IDEAS}

The IDEAS infrastructure was developed over a period of several years. Through IDEAS, we are able to support and promote student and faculty involvement in community-based projects, locally and internationally. The IDEAS program's director provides administrative and logistical support for courses in which community-based projects are a major component. Serving as community partner liaison, program staff initiates contact with new partners and manages longterm relationships with existing partners. For international projects, the program staff guides students through the approval and preparation process as per university travel policies, and serves as point of contact to monitor and manage the health and safety of students traveling abroad. The program staff also assists in managing details of grant projects related to the effort and studying how involvement in community projects affects student academic success and retention. Grant support includes the development and management of surveys and databases, budget management, data analysis, and reporting.

Funding was obtained through multiple sources including the federal government (NSF), Santa Clara University (SCU), and local organizations. Seed money from local organizations including Hewlett-Packard (Technology for Teaching), and S.D. Bechtel, Jr. (Integrating Community Based Learning Projects in the School of Engineering) enabled the initial offering of a community-based projects course, and the purchase of test equipment and project materials. Subsequent funding from an NSF DUE grant (CLEER: Community Learning Enabling 
Engineering Reform), and an NSF-CCLI grant (Pathways to Meaningful Learning) enabled the hiring of administrative staff to develop and manage the program; initial responsibilities included database and website development, and the setup of a dedicated work area for community-based projects. Ongoing support from Santa Clara University (Center for Science Technology \& Society, Technology Steering Committee, and the School of Engineering) has included funding for project materials, Zipcar use, and international travel for overseas projects.

Prior to IDEAS, the majority of the engineering community-based projects have been senior capstone projects or the results of student involvement in faculty driven projects in courses. Many of the senior design projects were very individual and did not grow from community partnerships with the school of engineering. With the development of a course (described later), open to all majors, it is possible for a student to engage in projects that meet the specific needs of a partner community. The IDEAS program provides the infrastructure necessary to develop and maintain these community partnerships, bringing continuity and making interdisciplinary projects available to the community based projects course as well as to faculty interested in projects for other classes. The program not only continues to support the ongoing faculty and student projects, but fosters strong ties to the community and has become the clearinghouse for resources and information regarding community projects.

\section{Senior Design Capstone Projects}

From 2009 to 2013, IDEAS has supported 35 community-based projects in senior design - 24 international, eleven in the United States. The local projects have often involved an education component, including demonstration units, or curriculum, for example, to teach concepts of renewable energy. Other projects have contributed to the education of developmentally or physically disabled adults. The 24 international projects were completed in eight different countries (students have worked on projects in India; Nepal; four countries in Africa: Ghana, Rwanda, Uganda, Zambia; and Honduras and Nicaragua in Central America). Many of the international projects address problems in water quality and distribution, inexpensive and readily available construction materials, or the redesign of tools/devices or mobile applications to increase income and improve livelihood. The projects often involve student travel to the country to research local materials and meet with the end-users in the community as well as the local trades-people to gather input and obtain feedback on ideas and design prototypes. Student work often includes training and documentation to sustain the product of their efforts.

Although these senior design projects were very impactful to the participating students, not all students were reaping the benefits of these community-based projects. We felt that all students would benefit from having a real-world design experience prior to their final year of school.

\section{INTERDISCIPLINARY COURSE DEVELOPMENT}

The Jesuit tradition at SCU aims to develop our students beyond the standard ABET soft skills of teamwork and life-long learning. We also "aim to instill the knowledge, habits of thought and action, and orientation to society that we believe will best prepare our students for life."vii Santa Clara University's curriculum is centered on the three C's of Competence, Conscience, and Compassion. Our program prepares engineering students to not only be proficient in engineering and science principles but to be aware of the interplay among science, technology, and society. 
Towards that goal, the university has developed a core education experience that includes requirements in "Experiential Learning for Social Justice", "Science, Technology, and Society," and "Civic Engagement," as well as other more traditional areas. The civic engagement outcomes that the students are required to have is defined as: the ability to work with the community, develop a realization of their vocation, and to develop an understanding of the civic bodies who oversee projects that impact the public. The IDEAS program strives to meet the intent of the Experiential Learning for Social Justice and Civil Engagement requirement using the definition of civic engagement as offered in the book Civic Engagement and Higher Education, "working to make a difference in the civic life of our communities and developing the combination of knowledge, skills, values and motivation to make that difference. It means promoting the quality of life in a community, through both political and non-political processes.",viii

In order to meet these university requirements as well as promote the integration of engineering concepts into service learning projects and meet our goal of providing the opportunity for EVERY student to participate in a community-based project, we developed a course "Engineering projects for the community" (ENGR 110). The course aims to create an authentic learning experience for engineering undergraduates that allows students to work in teams to develop and apply their technical knowledge in STEM disciplines and workforce skills through real-world projects that serve the community. Structured reflections are a key component of the course, allowing students the opportunity reflect on the possible impacts of their chosen vocation and discover how the various components of their education relate. The course objectives are given below.

As a result of this course the students will:

1. Gain practical engineering experience working on a project in the community.

2. Develop project management, organizational, and leadership skills.

3. Develop effective listening and collaboration skills while working with customers.

4. Design a service or product using the engineering design process

5. Recognize and summarize ethical responsibilities of engineers.

This course is two units, and is offered in a three-hour laboratory format. It meets different graduation requirements for different majors. For example, it counts as "professional development" for electrical engineers, "integrated education" for computer engineers, and can count as a technical elective for other majors. This course can be taken by any major in the university, and satisfies the civic engagement requirement of the university core.

In ENGR 110, the students are provided a genuine experience of working with a community partner on a real-world project. The faculty teaching the class work closely with the student teams and the partners to establish sound technical outcomes. The relationship with these community partners is established and nurtured by the IDEAS staff person who acts a liaison among the faculty, the students and the partner. After meeting with all the clients, students selfselect the project they find the most interesting, which often results in interdisciplinary teams of both upper and lower division students. Students then meet multiple times with their chosen community partners, including site visits, to ensure that students have clearly identified the engineering problem the client needs solved, determined any constraints at the site that could 
impact possible solutions, and received client feedback on design options and plans for final deployment of the solution.

Integrated course assignments require students to write four narrative reflections on Community Partnerships, Civic Engagement, Societal Impact and Ethical Issues, and Overall Learning Gains in reference to their projects. Students are instructed that the narratives should include their observations and experiences as it relates to participating in a real-world project from start to finish, highlight their thought process during the design phase, and identify the connections they make to what they've learned in this course and in prior courses. The reflections often include those components of the project that were unexpected, typically in relation to ethics and civic engagement. Most students are unaware of existing codes and regulations and the conflicts these can cause between project feasibility, consumer safety and cost.

Throughout the course, faculty supervise the student teams to ensure that the quality of the end product not only satisfies of the community partner but also meets the standards of the SOE. The partnership requires deliverables from all parties. The engineering students provide a comprehensive conceptual design based on creative problem solving and preliminary impact analysis with complete design details, a significant portion of the hardware/software for the project, and a demonstration of the design along with a design report. The community partner provides a review of their experience and satisfaction with the project results.

\section{COMMUNITY PARTNER EXPERIENCE \& IMPACT}

Several times per year, to prepare for ENGR 110, the IDEAS Program Coordinator visits new community organizations in search of potential projects for engineering students. We approach non-profit organizations in the community explaining our organization, summarizing some projects that may be of interest to the organization, and inquire about their needs and potential projects for undergraduate engineering students.

Over the years, we have had community partners with projects in many different areas including but not limited to sustainable energy solutions, educational displays and demonstration units, devices and computer programs for the developmentally or physically disabled, educational websites, mobile applications, online databases, and development of hands-on science lesson plans. These projects have contributed significantly to the partner organization or their programs, building on the tools and educational materials used in their programs enhancing the service to the communities they serve. At the end of each quarter we solicit feedback through the Community Partner Questionnaire, as shown Table 1. 
TABLE I

ENGR 110 COMMUNITY PARTNER QUESTIONNAIRE RESUlTS FOR 2013-14 (N=14)

\begin{tabular}{|l|c|}
\hline $\begin{array}{l}\text { Question: Please rate your level of involvement with students working on the project this } \\
\text { quarter. }\end{array}$ & Average \\
\hline $\begin{array}{l}\text { BASED ON A LIKERT SCALE OF 0 TO 3 WHERE 0 IS NOT APPLICABLE, 1 IS NOT INVOLVED, 2 IS } \\
\text { SOMEWHAT INVOLVED AND 3 IS VERY INVOLVED. }\end{array}$ & 2.79 \\
\hline Defined problem & 2.57 \\
\hline Discussed problem constraints & 2.57 \\
\hline Provided feedback on possible solutions & 2.00 \\
\hline Helped select the chosen design & 2.00 \\
\hline Evaluated prototypes & 2.50 \\
\hline Attended final group/team presentation & 2.18 \\
\hline Assisted during design implementation & Average \\
\hline \multicolumn{2}{|l|}{ Question: Evaluate your level of satisfaction working with the student project team: } \\
\hline BASED ON A LIKERT SCALE OF 0 TO 4 WHERE 0 IS DISSATISFIED, 1 IS SOMEWHAT DISSATISFIED, IS \\
NEUTRAL AND 4 IS SATISFIED. & 3.71 \\
\hline Communication with student team & 3.93 \\
\hline Responsiveness of team to organizational needs and interests & 3.86 \\
\hline Professionalism of team & 3.86 \\
\hline Amount of time required to manage team & 3.71 \\
\hline Skill level of team & 3.71 \\
\hline Quality of work & 3.93 \\
\hline Overall experience & \\
\hline
\end{tabular}

Feedback is used to improve the project experience for community partners and assists in the development of long-term relationships, which we feel results in:

- A greater impact to the partner community.

- A greater potential for steady stream of projects for students.

- An opportunity for students to have a realistic, real-world engineering experience.

- The creation of long-term projects that can extend over multiple quarters.

- An opportunity for students to experience how a long-term project with deliverables and deadlines proceeds and how they participate in the iterative process of design and implementation.

- A greater partner awareness of the process and time commitment that leads to an improved interaction between the partner, IDEAS, and the students.

- Opportunities for partners to request new projects that address improvements to earlier projects or sustainability/maintenance issues.

- An improved awareness of the impact of prior projects on the community, which in turn empowers the current students. 
We have developed long-term partnerships with five organizations resulting in a continuous stream of student projects. In turn, the completion of multiple projects has resulted in significant impact to these organizations and programs that serve the public.

Our long term partners include: Billy Jones Wildcat Railroad, Guadalupe River Park Conservancy, Peterson Middle School, Santa Clara Adult Education, and Walden West Outdoor Science School. Descriptions of their programs, the community they serve, and overview of their projects is provided below.

\section{BILLY JONES WILDCAT RAILROAD}

The Billy Jones Wildcat Railroad (BJWRR) exists as a means to preserve history and educate the public about the history of railroads (http://bjwrr.org). The BJWRR operates a park railroad system using one-third scale locomotives. The steam and diesel locomotives are from the early 1900's and documentation and specifications are limited or non-existent. SCU Engineering students have been involved in six projects over a period of three years providing data and information needed for regulatory compliance and planning. Student projects for the BJWRR have included: a survey of the railroad tracks in the park, an updated webpage design, a study of water and water treatments used in steam engines, a weight estimation of the locomotives, and horsepower measurement and determination of locomotive efficiency.

\section{THE GUADALUPE RIVER PARK CONSERVANCY}

The Guadalupe River Park Conservancy (www.grpg.org) provides community leadership for the development and active use of the Guadalupe River Park \& Gardens. The Guadalupe River provides an outdoor laboratory for science experiments for school children. Over the past three years, SCU engineering students have completed eight projects. Some of these include devices to enhance access, such as a portable ladder down steep inclines to the river and a boardwalk to provide wheelchair access into the orchard. Through a realistic and functional table-top model, one student project demonstrates how the culverts function to prevent flooding of the city during heavy rains. Another project developed a curriculum unit on flood control engineering. Students have built a solar charging system used to power instrumentation such as battery-powered microscopes, which are used for experiments down at the river's edge. An additional project involved developing solutions to connect two discontinuous sections of the Guadalupe River trail.

\section{PETERSON MIDDLE SCHOOL}

Peterson Middle School has a two-acre on-site Nature Center, which serves as a rich educational resource for all students in its district. The Nature Center was developed by two science teachers to enhance science education during a period of educational budget cuts. The Nature Center has been influential in teaching students about nature and environmental science through field trips and a highly interactive website. Over the past five years, SCU engineering students have worked on over 10 projects that have enhanced the educational resources available on the Nature Center website. Projects include: wireless connectivity within the Nature Center, sensors to measure temperature and dissolved oxygen in the ponds within the Nature Center, webcams to monitor wildlife activity, a housing for an underwater camera to monitor 'traffic' of fish and 
turtles passing from one pond to another, and an online Dichotomous Tree Key to assist in identification of the many types of trees present in the Nature Center.

\section{SANTA CLARA ADULT EDUCATION}

Santa Clara Adult Education (www.santaclaraadulted.org) offers courses in personal enrichment, as well as specialized programs to serve individuals with cognitive, developmental or physical disabilities. The mission of Santa Clara Adult Education is to "empower adults of all ages and abilities to succeed in an ever-changing world". ix Students worked on both hardware and software assistive technologies for the students in the specialized programs. The fifteen projects completed over the past six years have included software (including mobile apps) to help individuals learn how to handle money transactions, develop their vocabulary, or serve as a "guide" when using public transit; hardware that enabled physical interface with a computer; and devices using RFID tag technologies to aid the visually impaired navigate a room.

\section{WALDEN WEST OUTDOOR SCIENCE SCHOOL}

Walden West Outdoor Science School (www.waldenwest.org) operates a year-round, outdoor, science camp focused on hands-on environmental education, serving nearly 11,000 5th and 6th graders annually. SCU student projects align with Walden West's mission of "teaching science today, changing the world tomorrow". Eleven projects in Engr110 and five senior design projects have been completed at Walden West over the past 6 years. Projects include devices to demonstrate various alternative energy technologies including a bicycle-powered generator, a hydroelectric power demo unit, a solar-powered water pumping system (including a complementary hands-on curriculum), and a windmill. Other projects include a bio-digester, rainwater collection, pond aeration methodology to enhance water quality, and an online "virtual" tour of the Abby Sobrato Science \& Sustainability Center located at Walden West.

\section{COMMUNITY PARTNER COMMENTS}

Below are some comments received from partners provided through the Community Partner Questionnaire, in response to this question:

Has working with SCU Engineering students enabled you to improve your services to the community?

"The working flood control model will allow us to better serve school groups participating in our education programs, especially with the transition to the new state curriculum standards that calls for more tools such as this."

"Our Master Plan committee has been working on the connectivity of the trail for years. Coming up with solutions helps us provide a vital recreational and commuter amenity to the community. This is a major goal of the Conservancy."

"This project allows us to reach middle to high school students and apply STEM skills."

"With the sensor on the turtles back, we will start publishing the raw data on the Nature Area server. The schools in the district can then download the data and use it in the science classes." 
And, comments to this question:

Has your understanding of engineering changed as a result of this experience?

"The variety of talents and majors of the students contributed greatly to the project! I was impressed how each student contributed from their area of expertise! We are very grateful for the experience and are quite sure these students will make excellent engineers. Thank you!"

"I feel the value in an exercise such as this was having them (the students) learn about all the constraints such as permitting, meeting the needs of all the stakeholders, as well as physical challenges. They had to think outside the box and look at it from all angles. Quite a challenge!"

\section{IMPACT ON STUDENT LEARNING}

Since winter 2009, 170 students have enrolled in Engr110 to complete a total of 71 projects involving thirteen local non-profit organizations. These projects are in addition to the 35 senior design projects that were community-based. As noted earlier, one motivator for developing the IDEAS program, which supports the ENGR 110 course, was the belief that female and underrepresented groups were attracted to these service projects and a structured program that offered these experiences would improve the success and retention of these students.

According to the National Science Board, only 3.9 percent of the incoming female freshmen chose an engineering major during the $2009-2012$ period as compared to 18.7 percent of the incoming freshman males. ${ }^{x i}$ Female enrollments in the SOE during the period the class has been offered have averaged 25 percent, while the ENGR 110 course enrolled an average 32 percent women. This supports our belief that female students are attracted to community-based projects. The course also attracted a greater percentage of under-represented students than the averages at SCU. Figure 1 shows the percent distribution of race in the course as reported by 128 out of 170 students in comparison to the School of Engineering enrollment for the same period. Forty-two students chose not to indicate race on course surveys and were not included in the percent breakdown. As the figure shows, the course attracts a higher percentage of under-represented students than the typical student enrollment. Specifically African American, Native Hawaiian/Pacific Islander, American Indian/Native Alaskan, and Hispanic enrollment in ENGR 110 is 23.4 percent of the total course enrollment. Enrollment of this same demographic for the same period in the School of Engineering is eighteen percent. 


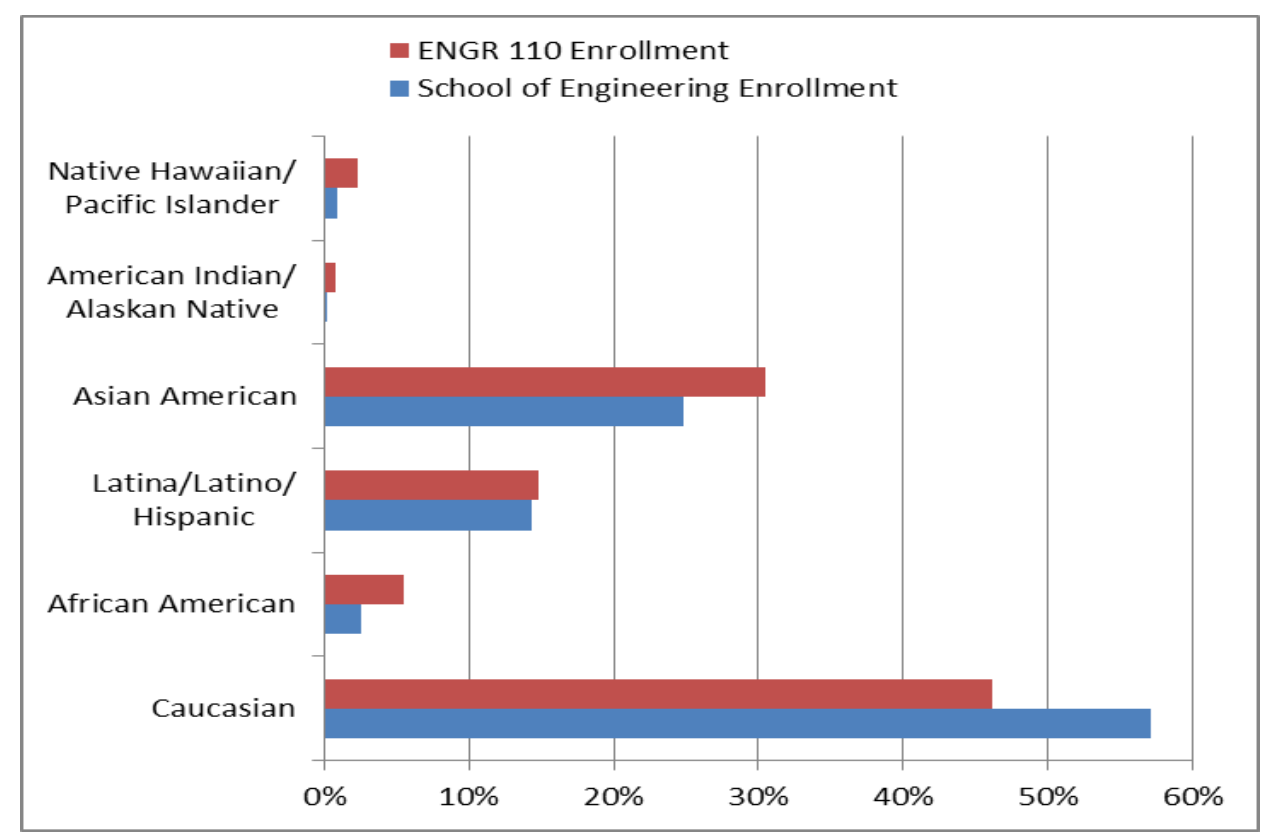

FIGURE 1:

COMPARISON OF ENROLLMENT PERCENTAGE IN ENGR 110 VERSUS SCHOOL OF ENGINEERING ENROLLMENT FOR THE PERIOD OF FALL 2009 TO SPRING 2014

In order to see the effectiveness of the ENGR110 course in achieving its learning outcomes, we administer surveys before the quarter begins and at the end of the quarter. Table 1 shows student survey responses over two academic years regarding the students' perception of their ability to complete course learning objectives. Survey questions did not address the final course objective regarding students' recognition of an engineer's ethical responsibilities. Student reflections were used to assess this outcome. 


\section{TABLE II}

ENGR 110 STUDENT SURVEY SCORES (N=64 FOR INTRO AND N=54 FOR EXIT) BASED ON A LIKERT SCALE OF 1 TO 4 WHERE 1 IS NOT DEVELOPED, 2 IS UNDER DEVELOPED, 3 IS DEVELOPED AND 4 IS STRONGLY DEVELOPED

\begin{tabular}{|c|c|c|}
\hline Question: Please rate your skills and abilities in the following areas & INTRO & EXIT \\
\hline \multicolumn{3}{|l|}{$\begin{array}{l}\text { Objective 1: Gain practical engineering experience working on a project in the } \\
\text { community. }\end{array}$} \\
\hline Solving engineering homework problems. & 2.84 & 2.94 \\
\hline Finding solutions to open-ended engineering problems. & 2.7 & 2.89 \\
\hline Learning in engineering classrooms about the engineering design process. & 2.78 & 3.06 \\
\hline Working with cutting edge technology. & 2.34 & 2.52 \\
\hline \multicolumn{3}{|l|}{$\begin{array}{l}\text { Objective 2: Develop project management, organizational, and leadership } \\
\text { skills }\end{array}$} \\
\hline $\begin{array}{l}\text { Developing an engineering plan that will lead to a solution to an engineering } \\
\text { problem. }\end{array}$ & 2.57 & 2.93 \\
\hline Working well with a team on an engineering project. & 3.15 & 3.35 \\
\hline Taking a leadership role when working with others on an engineering project. & 2.87 & 3.17 \\
\hline \multicolumn{3}{|l|}{$\begin{array}{l}\text { Objective 3: Develop effective listening and collaboration skills while working } \\
\text { with customers }\end{array}$} \\
\hline Orally communicating engineering ideas to practicing engineers. & 2.62 & 2.98 \\
\hline Communicating engineering ideas in written form to practicing engineers. & 2.42 & 2.78 \\
\hline Orally communicating engineering ideas to non-engineers. & 2.89 & 3.11 \\
\hline Communicating engineering ideas in written form to non-engineers. & 2.51 & 2.91 \\
\hline Working with members in the community to define project requirements. & 2.43 & 3.06 \\
\hline \multicolumn{3}{|l|}{ Objective 4: Design a service or product using the engineering design process } \\
\hline $\begin{array}{l}\text { Producing a device or prototype that will have an impact on your field of } \\
\text { engineering. }\end{array}$ & 2.1 & 2.39 \\
\hline Developing an innovative or unique concept. & 2.54 & 2.85 \\
\hline Conceptualizing a unique design to solve an engineering problem. & 2.57 & 2.96 \\
\hline
\end{tabular}


As described earlier, students write narratives that describe their thinking, their observations and experiences, and the connections they make to what they've learned in this course and in prior courses. Some examples of their reflections are provided below. In addition to reflecting on their overall awareness of ethical issues and the societal impact of engineering, they write narratives on community partnerships, civic engagement, and overall learning gains in reference to their projects.

One student reflected on how the community partnership helped him learn more about the interplay between engineering and society:

"These partners have shared their formal and informal knowledge about their various specialties, about their relationship with the community, and about their hopes in partnering with our class. While many partners are not technically minded, the knowledge they possessed, as well as their need for engineering projects, gave light to the role of engineering within society as a whole. Talking with community partners has emphasized the need for empathy within engineering. It is important to learn and understand who you are engineering for."

Reflecting on the environmental implications of the trail connector for Guadalupe River Park Conservancy, a student mentioned that:

"A policy that plays a direct role in directing where our project direction goes is the protection of the riparian habitat. With the restriction of not harming the surrounding wildlife in the affected area, it makes it difficult to design anything that can use the bank of the river as support for a cantilevered bridge. If we were to implement a cantilevered bridge by putting supports into the bank, the roots of trees that have been growing there may be harmed and ultimately cause the trees to fall down, harming the surrounding wildlife, which we want to avoid at all costs."

Reflecting on community resources relevant to his project, a student commented:

"... the American Foundation for the Blind offers technology evaluations which aim to show companies how "to get accessible products into the hands of people with vision loss - and maximize profits". AFB has helped bring products like cell phones, insulin gadgets, kitchen appliances, and office equipment into the marketplace, which are able to accommodate to the needs of the visually impaired."

When considering applicable regulations for the Walden West pond aeration project, a student commented:

"In order to proceed with our project our team must also follow and understand the rules and regulations of the California Environmental Quality Act (CEQA). According to the rules specified by the CEQA, we are a private agency undertaking an activity defined as a 'project' (which may cause either a direct physical change in the environment or a reasonably foreseeable indirect change in the environment). Therefore it is necessary to gain discretionary approval from a government agency. Detailed projections of the oxygenator systems impact on its surrounding environment must be documented in order to gain approval and support before construction begins.... However a project may not be approved as submitted if feasible alternatives or mitigation measures are able to substantially lessen the environmental impacts on the project."

Another student added:

"The pond is fed artificially by a pipe from the nearby creek and has only one inlet at 40 gallons per minute. This creates an issue due to the fact that there cannot be an increased flow into the pond. ... the option of using an aeration pump to de-stratify and stabilize the pond 
would be nonintrusive to the existing structure and create a habitat conducive to the local wildlife 's health as well as the visitor's enjoyment"

Commenting on the lack of financial support for engaging science education, one student working with Peterson Middle School shared:

"... politicians have the responsibility to route funding to the places that need it most. It's no secret that education has been getting the lesser allocations of funding, with government programs encouraging memorization and standardization (like No Child Left Behind) over engaging educational alternatives. This gives teachers and administrators the task of educating children to the specifications of the government, rather than teaching to the actual needs of the child."

The impact of real world projects in reinforcing theoretical learning was evident in this student reflection:

"I also learned a fair bit about electricity and off grid power storage, and safety components related to this. I have developed a real world notion of how much power a watt is. Now I could tell you a water pump is probably around 30 watts, a light bulb is around 15 watts, and a microscope is up to 50 watts. Through this course, I applied numbers to real world situations. My confidence has been improved and after this project and I know the time commitment a real project takes."

While reflecting on the learning experience, one student said:

"This course actually greatly improved my engineering skills on a professional level. This was the first engineering project I have been given in which no firm guidelines were assigned, therefore expecting us to recall all of our previous engineering studies and apply them to our project needs. Our project involved pond aeration, a subject I had very little background knowledge on, so I gained great experience in researching aeration concepts as well as applying my background knowledge in fluid transport. Working for an actual client rather than being given a hypothetical situation also gave great experience in what it was actually like to be a consulting engineer and cater to the needs of someone else. Client interaction reinforced the importance of being professional and following through on benchmark completion. Even though this course was frustrating at times, it was a good learning experience to undergo a real-life engineering project and be forced to troubleshoot any obstacles we encountered. My group worked hard on this project, and is genuinely proud of the result, granting sufficient personal satisfaction at the completion of this class."

\section{Challenges}

Prior to the establishment of the IDEAS infrastructure and the ENGR 110 course, student, involvement in community-based projects was dependent on faculty interest or student club activity. An individualized and uncoordinated approach causes challenges in creating a holistic student experience that requires student reflection on their learning gains as well as their ethical and civic responsibilities.

The creation of the ENGR 110 course provides students with a structured experience that includes the critical reflections. However the development of this course was not without its challenges. Completing projects in the ten-week time period of our quarter system can be difficult. As such, the course was modified to allow for longer duration projects with students able to take the course multiple times for credit or to identify specific project deliverables that are reasonable for the ten week period and allow the project to be continued the following term 
by new students. Often lower division students without the necessary technical skills to complete a project enroll in the course. This issue is addressed in two ways, either by reducing the project scope for that particular quarter or by pairing these students with upper division students who assume leadership roles. Since many of these projects extend into several quarters, the lower division students are able to take the course again and continue their previous projects, but now in a leadership role. Six projects have been of sufficient depth and challenge to be extended into senior design capstone projects.

A continuing challenge of the course is the alignment of projects with student majors. Since the course is open to all students within the SOE, course instructors do not know the students' majors until the enrollment period ends. At the same time, the IDEAS staff is working closely with existing partners and approaching new partners to ensure a varied pool of possible projects.

Course logistics in terms of facilitating face to face meetings between students and clients can also be a challenge. The IDEAS staff organizes the initial site visits that allow our clients to introduce their projects to all the students in the course. Course instructors and students volunteer to drive and can use a departmental Zipcar if they have set up an account in advance. Community partners also agree to visit campus a minimum of two times for an organized design review and the final design presentations. Students are required to drive themselves to customer sites with either their own car or using the available Zipcars.

At SCU, senior projects are showcased during the annual Senior Design Conference, which requires students to present their work in a conference like setting with alumni panels in each presentation session that question the students on their projects and judge the presentations. This is a highly promoted and anticipated event in the SOE. Promotion of the ENGR 110 course among students is currently done in our first year engineering course and by word of mouth among students. The only promotion to our school and university colleagues consists of select invitations to the final design presentations. Discussions are in progress on ways to promote and showcase the course and final projects.

\section{CONCLUSIONS}

We have described our experience in developing the institutional infrastructure required to support students working on community-based projects, and the challenges and rewards of investing in such an endeavor. The all-important relationships built among the community, the engineering school, and the students involved have proven to be the necessary key to the success of such a program. We have shown the benefits to students, to the communities, and to the profession in this win-win-win effort. The students learn the positive real world impact of engineering; the communities gain from the implementation of projects they could not otherwise afford; and the profession gains by encouraging more students from underrepresented groups to persist in engineering. In addition to the obvious impact of involving a disproportionate number of underrepresented students in these projects on the number of those students who continue into the field, the community learns about engineering and who can "do" engineering - expanding the population that may consider the study of engineering in the future. Additional information about this experience has been reported in the engineering education conferences. 


\section{Acknowledgments for Funding Received}

This research, course and infrastructure development was supported in part by two National Science Foundation grants (DUE-0431975 and CCLI-0737110). Any opinions, findings, and conclusions or recommendations expressed in this material are those of the authors and do not necessarily reflect the views of the National Science Foundation.

Significant funding was also received through awards and grants received from the following local organizations: Hewlett-Packard, Cisco, the Institute for Women and Technology (now the Anita Borg Institute), and the SD Bechtel, Jr. Foundation.

Additional ongoing support includes grant funding and other resources received through several departments and organizations within Santa Clara University: the School of Engineering; the Center for Science, Technology, and Society; and the Technology Steering Committee.

\section{REFERENCES}

${ }^{\mathrm{i}}$ Benjamin Franklin. BrainyQuote.com, Xplore Inc, 2014. http://www.brainyquote.com/quotes/quotes/b/benjaminfr383997.html, retrieved on October 12, 2014.

${ }^{i i}$ A. Astin, L. Vogelgesang, E. Ikeda and J. Yee, "How Service Learning Affects Students", Los Angeles: Higher Education Research Institute, UCLA, 2000

iii Accreditation Board for Engineering and. Techonology, Engineering Criteria 2000, Baltimore: Author, 1997

${ }^{\text {iv }}$ Kline, Nancy, Time to Think: Listening to Ignite the Human Mind. Cassell, London, 1999

${ }^{v}$ Davis, Ruth, "Community-Based Learning Develops Diverse Engineering Workforce", Innovations 2005 - Special Edition: World Innovations in Engineering Education and Research, Begell House Publishing, 2005, pg. 7-16

vi “IDEAS: Interdisciplinary Design Engineering and Service”, http://www.scu.edu/engineering/ideas/ Retrieved on September 26, 2014

${ }^{\text {vii }}$ SCU University, "2013/2014 Core Curriculum Guide", Retrieved on October 10, 2014 from http://www.scu.edu/provost/ugst/core/upload/Core-Guide-2013-2014.pdf

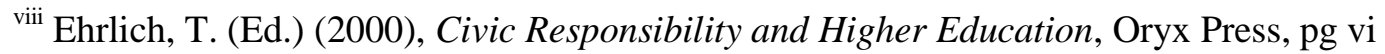

${ }^{\text {ix }}$ www.santaclaraadulted.org Retrieved October 10, 2014

${ }^{\mathrm{x}}$ www.waldenwest.org Retrieved October 10, 2014

${ }^{\mathrm{xi}}$ National Science Board, Science and Engineering Indicators 2014. Arlington, VA: National Science Foundation, Retrieved on October $2^{\text {nd }}, 2014$ from http://www.nsf.gov/statistics/seind14/index.cfm/etc/figures.htm\#chp2 